\title{
EXERGETIC AND ENERGETIC EVALUATION OF AN INNOVATIVE SOLAR AIR HEATING SYSTEM COATED WITH GRAPHENE AND COPPER OXIDE NANO- PARTICLES
}

\author{
Rahul Kumar ${ }^{1}$, Sujit Kumar Verma ${ }^{1}$
}

\begin{abstract}
In the $21^{\text {th }}$ century, renewable energy has to play very important role in socio-economic and industrial development. This paper evaluates the exergy- energy analysis, which is based on the second law of thermodynamics. The triangular solar heater is developed to determine the heat transfer rate, thermal efficiency, exergy efficiency and Bejan number. In addition, we have examined the effects of entropy generation with respect to solar radiation and ambient temperature of air. Absorber plates coated with graphene and copper oxide nano-particles by the different percentages $(0.1 \%, 0.2 \%, 0.3 \% \& 0.4 \%)$ doped into black paint which increases the absorption of heat. The Reynolds number $\left(4500 \leq R_{e} \leq 22700\right)$ varies for the fixed selective coating on absorber plate and mass flow rate. The experimental observations were performed for constant mass flow rate of air ranging from $0.0035 \mathrm{~kg} / \mathrm{s} \mathrm{to} 0.018 \mathrm{~kg} / \mathrm{s}$. The experimental result gives the average thermal efficiency enhancement of $3.58 \%$ for $0.3 \%$ graphene/CuO-black paint. Entropy generation is more for $0.1 \%$ and minimum for $0.3 \%$ graphene/CuO-black paint coating. The entropy generation analysis concludes that the entropy generation increases with increasing the mass flow rate. Exergy efficiency enhancement can be found $0.169 \%$ for $0.3 \%$ with respect to $0.1 \%$ graphene/CuO-black paint.
\end{abstract}

Keywords: Triangular Solar Air Heater, Entropy Generation, Solar Intensity, Nano-particles, Absorber Plate Coating, Heat and Mass Transfer

\section{INTRODUCTION}

The solar air heating systems are highly effective and promising in absorption of solar energy. It convert solar energy to heat with the help of flowing air. The solar thermal system gives the hot air in the output. This hot air can be used for space heating or drying purposes. These systems can produce thermal energy in the form of warm air at the output with the help of absorb solar radiation from the sun. This form of energy production, which is safe, clean, environmental friendly and it cannot produce any harmful effect on the environment. This energy can be used an extraordinarily in active and passive heating systems [1]. TSAH's main applications include space heating, crop drying, textiles and solar dryers. These are cost effective devices and easy to manufacture, require less maintenance cost. The purpose of the device is to optimize the thermal and exergy efficiency, which is defined as the ratio of useful thermal energy output to that of incident radiation which available during day clear sky and day time. Intensity of solar radiation available and duration of availability depends upon latitude, longitude, local environmental conditions and season. Performance of TASH can be evaluated by its ability to convert incident solar energy into useful work. The amount of useful energy calculated by TSAH can be increased by increasing the velocity of flowing fluid as air through the inside passage of the TSAH [2].

The solar experiment device is similar to a heat exchanger device which converts solar radiation into heat energy. For the consideration of exergy performance of the triangular system, this is based on the second law of thermodynamics. Energy balance of incident radiation and its conversion into useful work is in accordance with first law of thermodynamics [3]. In the solar air heating system, absorber plate works as an absorbing surface which is coated with graphene and copper oxide nano-particles doped black paint. The coating on absorber plate has a good thermal conductivity to transfer the heat to the fluid used as an air [4]. In this presented experimental investigation, Bejan number gives a very good contribution in the study of performance evaluation. The Bejan number depends on entropy generation rate throughout the system. Also, Reynolds number and air transfer coefficients are increased as mass flow rate increases.

\section{EXTENDED LITERATURE REVIEW}

On the basis of literature survey of research contribution of many researchers in area of exergy and energy analysis on solar air heaters, it can be interpreted that minimization of entropy generation is the ultimate objective to 
enhance exergetic performance of SAH. Researchers have an alert on investigating the exergy efficiency, heat transfer and entropy generation for better improvement in the solar system.

Huseyin [5] performed experimental investigation on performance of flat plate SAH by using thermal energy storage as a paraffin wax (PCM) and finds latent heat storage technique for the greenhouse. It is to find that the heat stored $0.65-2.1 \mathrm{KW}$ and average daily exergy was stored $112 \mathrm{~W}-79.9 \mathrm{~W}$.

Tyagi et al. [2] investigated parametric analysis of the energetic performance of the concentrating type SAH. It based the analysis on the inlet fluid temperature and efficiency. They found that the exergy value depends on the solar intensity and it decreases exergy at the low value of intensity and exergy decreased at intensity value is increasing.

Gupta and Kaushik [6], an analytical exergy analysis shows the unique parameters like AR, collector plate area, and mass flow rate. They found that it achieves a higher exergy rate at a low valve of duct depth and high AR.

Singh et al. [7] performed theoretical investigation on effect of entropy generation and heat transfer in nano fluid. A finding of theoretical investigation reveals that entropy generation ratio is constant for particular system or it increases slowly.

Akpinar and Koçyiğit [8] performed experimental analysis on the performance of SAH with the several type of method and two mass flow rate. It has been inferred on the basis of experimental findings that, first law efficiency is varied between $20 \% \& 82 \%$ and second law shows efficiency changed $8.32 \%-44.0 \%$.

Ching et al. [9] presented a numerical investigation on right triangular enclosure through mixed convection heat and mass transfer is examined. Here the bottom surface maintained the uniform temperature. They found in results the increases of buoyancy ratio increases the heat and mass transfer rate for all values of Richards on number for every direction of sliding wall motion.

Sriromreun et al. [10] performed experimental and numerical study on the heat transfer enhancement in a channel with $Z$ shaped baffles. The effect of $Z$ baffle and height and pitch spacing length are examined. The phase $45 \mathrm{Z}$ baffle with larger e/H gives the higher friction loss and heat transfer.

Malvandi et al. [11] Present study based on the nanofluid effect on the boundary layer flow over plate and analyzes the entropy generation inside the boundary layer. They found that entropy generation is depending on the volume fraction of the nanofluid particle.

Parvin et al. [12] presented an experimental investigation on the entropy generation and heat transfer by forced convection. $\mathrm{Cu}$-water nano-fluid used as working fluid in experimental research. It is found that entropy generation rate increases as the Reynolds number and volume fraction $\mathrm{Cu}$-water nano-fluid.

Mahian et al. [13] performed an analytical study is for the entropy generation and heat transfer of nanofluid flow in a flat plate solar heater. $\mathrm{Al}_{2} \mathrm{O}_{3}$ /water used as a working nano-fluid. A result confirms that entropy generation decline with increase in concentration of nano-fluid. Absorber plate roughness increases the outlet temperature of fluid and it also increase the entropy generation.

Skullong et al. [14] the experimental study based on the heat transfer and turbulent flow in a solar air heater with wavy groove tarbulators. The air flow is maintained the Reynolds number varies 4000 to 21000.They found in results both the upper and lower walls of the test channel gives highest heat transfer rate and friction factor compared with smooth channel.

Shojaeizadehet al. [15] investigated exergetic analysis of a FPSC with $\mathrm{Al}_{2} \mathrm{O}_{3}$ /water nano-fluid like working fluid. It is observed that the magnitude of exergy efficiency changes with corresponding parameters like nano-particle volume concentration and mass flow rate of fluid. The rate of exergy efficiency is increased by $1 \%$ by using $\mathrm{Al}_{2} \mathrm{O}_{3} /$ water nano-fluid.

Bahrehmand et al. [16] performed mathematical simulation on effect of single and double glazing on performance analysis of solar system. Experimental findings are not in favour of using double glazing as it has an adverse effect on thermal efficiency of SAH.

Verma et al. [17] investigated on performance analysis of FPSC using $\mathrm{MgO}$ /water nano-fluid. Experimental results establish that thermal efficiency enhanced by $9.34 \%$ while exergy efficiency by $32.23 \%$ at $0.75 \%$ particle volume fraction and optimum flow condition 1.

Kalaiarasi et al. [18] performed experimental investigation on energy and exergy analysis of SAH. The study based on the design and sensible heat storage in SAH. They found the value of exergy and energy enhancement from $18.25 \%$ to $37.53 \%$ and $49.4 \%$ to $59.2 \%$ respectively.

Zhu et al. [19] performed experimental analysis on new type of SAH with micro heat pipe arrays. 
Researchers claims maximum thermal efficiency can be obtained up to $69 \%$ at a mass flow rate of air $290 \mathrm{~m} 3 / \mathrm{h}$.

Gill et al. [20] performed experimental investigation on the solar air heater having broken arc rib. Five type of broken rib on the roughened plate having gap position ranging 0.2-0.8 for Reynolds Number values 200016000. They found in result, in the presence of broken rib enhance the friction factor, Nusselt number and thermohydraulic performance up to $2.55,2.37$ and 1.94 respectively compared with smooth duct.

Ghiami and Ghiami [21] investigated thermal and exergy efficiency of energy storage system using PCM paraffin wax. Findings of investigation exhibits thermal efficiency $26.78 \%$ and enhancement in exergy efficiency has been $4.86 \%$ to $20.47 \%$. Optimum enhancement in exergy efficiency observed $20.47 \%$ at $0.017 \mathrm{~kg} / \mathrm{s}$.

Mesut Abuska [22] in experimental study shows the performance with the help of absorber plate roughness and mass flow rate. Absorber plate roughness provides turbulent air flow, and it increases the surface area. Experimental observation indicates that efficiency of SAH depends upon the solar radiation, mass flow rate and absorber plate roughness.

Kilic M. [23] investigated the heat transfer effect on the porous plate by transpiration cooling. A result establishes that the increase in the water flow rate induces a decrease in the surface temperature which increases the efficiency of the porous plate and the cooling efficiency of the device.

Kilic M. [24] the investigation based on the study of heat transfer from porous plate by the cooling medium as an air with different mass flow rate. Authors observed from the result increases the Reynolds number causes the increases the temperature of the surface of the porous plate and decreasing the efficiency of 13.7 percent but in case of water average surface temperature of the plate is decreases 1.1percent and efficiency increases 19.1 percent.

Mortazavi and Ameri[25] investigated performance of FPSC through thin metal sheet. Study based on the advanced energy analysis for FPSC through thin sheet of metal. Results establish that lesser exergy loss occurs with higher absorption efficiency absorber plate.

Kilic M. and Abdulvahitoglu[26] investigated the heat transfer from a heated surface with the help of nanofluids and swirling jets. Authors were used pure water, $\mathrm{Al}_{2} \mathrm{O}_{3}-\mathrm{H}_{2} \mathrm{O}, \mathrm{TiO}_{2}-\mathrm{H}_{2} \mathrm{O}$ for the heat transfer and fluid flow analysis It is determined that increasing the Reynolds number from $\mathrm{Re}=12000$ to 21000 causes an increase of 51.3 per cent on average of the Nusselt number.

Kilic M. and Ali H. [27] numerically investigated the heat enhancement and fluid flow from the heated surface by the use of three impinging jet with nanofluid. The study was based on the Al2O3-water, CuO-water, TiOwater, $\mathrm{Cu}$-water and pure water. The result shows that the use of $\mathrm{Cu}$-water nanofluid induces a rise of 2.2 per cent, 5.1 per cent, 4.6 per cent and 9.6 per cent on average Nusselt in comparison to CuO-water, TiO-water, $\mathrm{Al} 2 \mathrm{O} 3$-water and pure water.

Kumar and Layek [28] performed numerical optimization of the SAH with warped rib roughness on the absorber plate. Authors reported maximum increment in exergetic efficiency as $1.81 \%, 1.79 \%$ and $1.81 \%$ in comparison with a smooth plate for temperature rise parameter $0.0125 \mathrm{~m} 2 \mathrm{~K} / \mathrm{W}$.

Abdelkader et al. [29] conducted an investigation on effect of absorber plate coating in exergy efficiency . Here $4 \% \mathrm{CNTs} / \mathrm{CuO}$-black paint is used for a coating material which improves the performance of SAH. It shows exergy efficiency increased by $22.4 \%$. Inlet and outlet temperature difference is $22 \%$ based on the average result.

Nidhul et al. [30] performed CFD analysis on the triangular solar air heated duct with V-rib roughness. Authors varied the performance parameter, Reynolds Number, fixed relative pitch, relative rib height and pitch inclination. Experimental result confirms the maximum enhancement in exergetic efficiency was $23 \%$.

Šst et al. [31] carried an experimental study on the behaviour of selective graphene and copper oxide nano-particles coating on absorber plate. This coating is used for the anticorrosion material. The result shows good anticorrosion behaviour of graphene and copper oxide nano-particles compared to aluminium substrate.

Wang et al. [32] investigate to improve the efficiency of SAH by using S -shaped ribs on the absorber plate. It is found that the thermal efficiency was improved by $13 \%$ to $48 \%$ at pressure drop varies $15.8-30 \mathrm{~Pa}$.

Abo-Elfadl [33] the performance of double pass SAH were studied at different mass flow rates and compare the performance parameter with tubular and flat SAH. They found that tubular SAH efficiency is grater then flat SAH efficiency by $19.4 \%, 21 \%$, and $40.3 \%$ at inlet air flow rate $0.075 \mathrm{~kg} / \mathrm{s}, 0.05 \mathrm{~kg} / \mathrm{s} 0.025 \mathrm{~kg} / \mathrm{s}$ respectively. $\mathrm{H}$.

Hassan et al. [34] performed comparative analysis of SAH with tubular and flat SAH at varying flow rates. Observations reveals that average tubular SAH efficiency was about $83.6 \%, 76.3 \%$ and $59.8 \%$ corresponding to rate of flow at $0.075,0.05$ and $0.025 \mathrm{~kg} / \mathrm{s}$, respectively with an increase of $132.6 \%, 58.6 \%$, and $43.5 \%$, respectively compared to flat SAH and the daily top heat loss of tubular SAH is decreases $10 \%$ compared to flat SAH. 
Kumar R et al. [35] used triangular duct to find the thermal efficiency of solar heater .It was found the higher thermal efficiency at higher mass flow rate.

Kumar R et al. [36] investigated the performance of triangular solar heater using graphene nonmaterial embedded in black paint. It was found the maximum efficiency of the system is 48.23 percent at air velocity 1 $\mathrm{m} / \mathrm{sec}$.

Bensaci et al. [37] performed experimental and numerical investigation to improve the thermo-hydraulic performance of solar air heater. They have found that the optimum thermo-hydraulic performance factor is achieved where the baffles are located the first part of conduit and which occupy $50 \%$ of SAH.

Abdullah et al. [38] performed experimental study on the SAH to enhance the efficiency of heater. Authors have used an aluminum cans on the absorber plates as a tabulators. The comparison between with or without reflector were carried out. They found that the maximum daily efficiency of the anticipated SAH was $73.4 \%$ at $0.05 \mathrm{~kg} / \mathrm{s}$ for staggered heater equipped with guide vanes and external reflector.

Akhbari et al. [39] investigate the experimental data of a triangular channel SAH with U turn air flow pattern. They found that the maximum efficiency is obtained for the TASH at mass flow rate of $0.045 \mathrm{~kg} / \mathrm{s}$ and the result also reveals that, it require less area compare to flat $\mathrm{SAH}$ at same solar radiation.

Arunkumar et al. [40] in their analytical study for enhancement of the efficiency with the help of roughness employed on the absorber plate which increase the turbulence level of the air. Experimental observation support that some parameters are effective in performance enhancement. These are geometries used, design considerations, flow conditions and their heat transfer rate, turbulence, absorber plate temperature resulted in enhancement of the heat transfer rate from the absorber plate.

Darici and Kilic [41] investigated the performance of solar air collector by changing the geometry of absorber plate and the result were compared with the trapezoidal and flat absorber plates. Result establishes the maximum enhancement in temperature rise for trapezoidal plate was $9^{\circ} \mathrm{Cwith}$ respect to flat plate solar air collector at mass flow rate of $0.022 \mathrm{~kg} / \mathrm{s}$. It has been also observed for the trapezoidal absorber plate that average efficiency rise $63 \%$ at $0.044 \mathrm{~kg} / \mathrm{s}$ compare to flat plate collector.

Yildirim et al. [42] made the use of absorber plate with rib-groove geometry on absorber plate in solar air heater. Theoretical analysis was done by using energy balance equation and various parameters relative roughness height and roughness pitch and pitch to groove positions were investigated in the Reynolds number range between 3000 to 21000.Results were compared with those of flat plate solar air heater. It was found that by increasing groove position to pitch ratio the value of thermo hydraulic efficiency increases. Differential transform methods have also been applied on flat plate solar air heater whose absorber plate thickness is varied along its length.

Dutta and kundu [43]. The results obtained were validated using modified Bessel's function .It was concluded that temperature of absorber plate increases linearly along direction of heat flow. Solar radiation $600 \mathrm{~W} / \mathrm{m} 2$ and initial collector fluid temperature of $300 \mathrm{C}$ were taken.

Menni et al. [44] used four baffle plates in the passage of flow of air through the duct of rectangular section and performed its CFD analysis Ansys FLUENT software version 6.3.Aspect ratio and width to height ratio of 1.31 and 5.137 were taken respectively. The ratio of spacing between baffles and its height were taken as 0.972 . The research resulted into a finding that thermal enhancement factor TEF increases with increase in Reynolds number. Its maximum value was obtained when Reynolds number of 32000 was taken.

Singh et al. [45] analyzed experimentally the thermo hydraulic performance using triangular projections as roughness geometry on absorber plate of solar air heater. The roughness geometry resulted in increase in heat transfer, Nusselt number but also at the cost of some increase in friction factor value. Correlations were developed between friction factor and Reynolds number.

The aim of the paper is to investigate the thermal efficiency, exergy efficiency, entropy generation and Bejan number by the use of graphene/CuO nano-particles embedded into black paint coating on absorber surface. The main purpose of the study is to prepare a solar selective coating for absorber surface by using black paint and different percentage of hybrid nano-materials. This is to improve the exergy and energy performance of TSAH. In the numerical investigation, solar intensity, mass flow rate and ambient temperature of the fluid are taken as a variable parameter. The novelty of this study graphene/CuO nano-particles embedded into black paint have not used before at any study. In this paper, the effect of solar selective coating on the absorber surface has been investigated for thermal efficiency, exergy efficiency and entropy generation rate. 


\section{EXPERIMENTAL SETUP}

An experimental setup is designed, fabricated and tested in the solar research centre, department of mechanical engineering in GLA university, Mathura. In India Mathura has a good zone of solar intensity potential (Latitude and longitude coordinates are 27.49, 77.67). The average annual solar intensity is about $4.55 \mathrm{kWh} / \mathrm{m}^{2} / \mathrm{day}$. An experimental set-up is shown in Figure 1 \& Figure 2 and a schematic diagram of triangular solar air heater is in Figure 3. The experimental arrangement consists of an equilateral triangular section that is made-up by the aluminum sheet. The size of the triangular section is $1 \mathrm{~m} \times 0.6 \mathrm{~m} \times 0.52 \mathrm{~m}$ as well as hydraulic diameter is $0.352 \mathrm{~m}$ with an aspect ratio of the triangular segment is 1.15 . The inlet and outlet section distance end to end of the pipe are same. Therefore, the flow assumed within the triangular section is completely turbulent without slip at the wall and throughout the length of the test section, thermal properties are constant. In the inlet side of the section air is sucked with help of a blower at ambient condition.

In presented experimental investigation, we have used four types of absorber surfaces which have coated with graphene $/ \mathrm{CuO}$ nano-particles at a different percentage $(0.1 \%, 0.2 \%, 0.3 \% \& 0.4 \%)$ doped into black paint. The absorber plates are made of aluminum with selective coating on it. The absorber plate is a very important component of the triangular heater section, which absorbs the solar radiation from the sun. One side of the triangular section comprises a glass cover used as glazing although the other two side of triangular section are absorber plate.

Inlet and outlet temperature measured by the $\mathrm{K}$-type $(\mathrm{Ni}-\mathrm{Cr} / \mathrm{Ni}-\mathrm{Al})$ thermocouple were used. The solar intensity meter measures the solar radiation intensity on the glazing plate. Solarimeter placed on the glazing sheet at the same inclined plane. Inlet and outlet pressure has been measured by the micro manometer. For air speed measurement a digital anemometer was used. The output of the hot air is controlled by a control device at output section. The detailed design specifications of TSAH are given in

Table 1.The thermo- physical properties of the air are given in table 2.

Table 1. Detail specification of TSAH

\begin{tabular}{|l|c|c|}
\hline \multicolumn{1}{|c|}{ Specification } & Dimension & Unit \\
\hline Length of Triangular section & 1 & $\mathrm{~m}$ \\
\hline Length of triangle sides & 0.6 & $\mathrm{~m}$ \\
\hline Height of triangle & 0.52 & $\mathrm{~m}$ \\
\hline Hydraulic Diameter & 0.352 & $\mathrm{~m}$ \\
\hline Aspect ratio of TSAH & 1.15 & -- \\
\hline $\begin{array}{l}\text { Length of outlet and inlet section } \\
\text { of TSAH }\end{array}$ & 0.4 & $\mathrm{~m}$ \\
\hline Diameter of outlet and inlet pipe & 0.0635 & $\mathrm{~m}$ \\
\hline Back insulation thickness & 0.004 & $\mathrm{~m}$ \\
\hline Conductivity of Back Insulation & 0.04 & $\mathrm{~W} / \mathrm{m} \mathrm{K}$ \\
\hline Number of Glazing Plates & 1 & -- \\
\hline Glazing Plate Thickness & 0.004 & $\mathrm{~m}$ \\
\hline Glazing Plate area & 0.6 & $\mathrm{~m}^{2}$ \\
\hline Absorber plate area & 1.2 & $\mathrm{~m}^{2}$ \\
\hline Edge area of triangular section & 0.312 & $\mathrm{~m}^{2}$ \\
\hline
\end{tabular}

Table 2. Thermo-physical properties of air

\begin{tabular}{|l|c|c|}
\hline \multicolumn{1}{|c|}{ Specification } & Dimension & Unit \\
\hline Density & 1.125 & $\mathrm{~kg} / \mathrm{m}^{3}$ \\
\hline Specific Heat at Constant Pressure & 1.006 & $\mathrm{KJ} / \mathrm{kg}-\mathrm{k}$ \\
\hline Specific Heat at Constant Volume & 0.718 & $\mathrm{KJ} / \mathrm{kg}-\mathrm{k}$ \\
\hline Viscosity & $1.783 \times 10^{-5}$ & $\mathrm{~N} / \mathrm{m}^{2}$ \\
\hline Thermal Conductivity & 0.0262 & $\mathrm{w} / \mathrm{m} \mathrm{K}$ \\
\hline Ideal Gas Constant & 287 & $\mathrm{~J} / \mathrm{kg}-\mathrm{k}$ \\
\hline
\end{tabular}




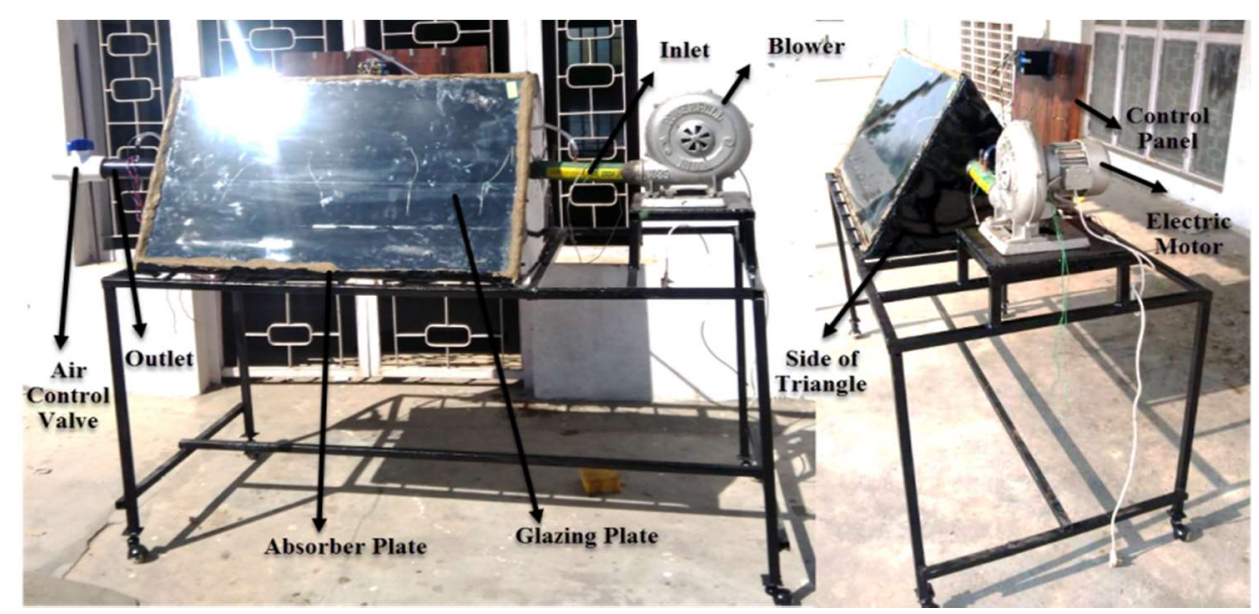

Figure 1. Experimental setup
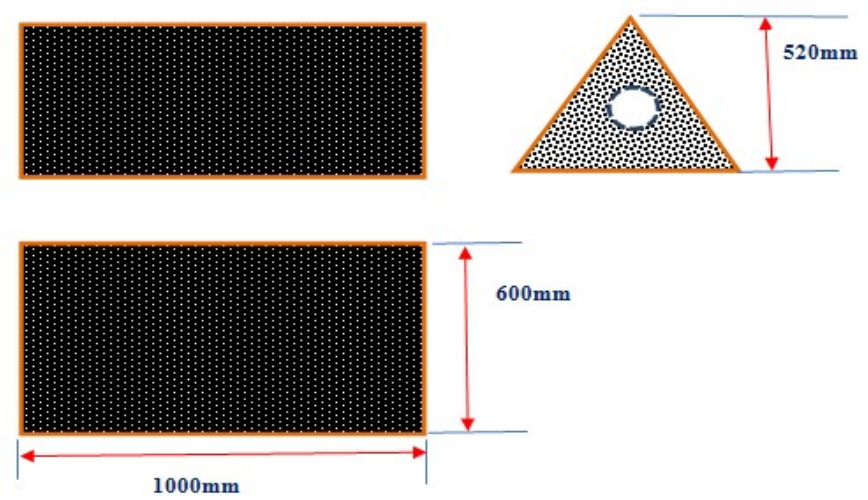

Figure 2. 2-D drawing of TSAH duct

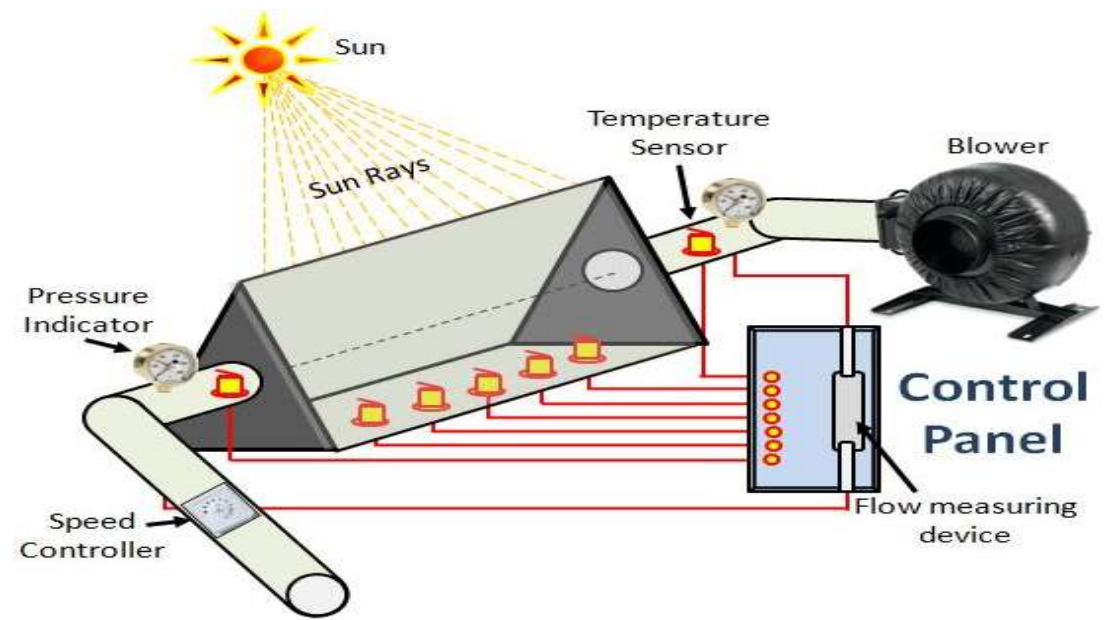

Figure 3. A schematic picture of TSAH

\section{NANO-PARTICLES COATING}

The graphene and copper oxide nanoparticle are used in the experiments to form a distinctive type of coating on the absorber plate. The hybrid nanomaterial is developed by the mass ratio of Graphene $20 \%$ and copper oxide $80 \%$. The magnetic stirring is used for the mixing the nanoparticle into black paint. The absorber plate is coated with black paint in which graphene and copper oxide nano-particles of different percentage were doped. Initially, the percentage of graphene and copper oxide nano-particles is doped black paint to increase the absorptivity and decrease the emissivity of absorber plate. This graphene (purchased from the Platonic Nanotech Private Limited-India) is produced by the chemical exfoliation method, is very fluffy, very light powder in black color and $\mathrm{CuO}$ is a black colour powder. The different percentage absorption of 0.1 per cent, 0.2 per cent, 0.3 per cent and 0.4 per cent of the hybrid coating material were $0.946,0.949,0.952$ and 0.955 respectively. For emissivity values of $0.122,0.134,0.129$ 
and 0.12 with respect to different percentages of 0.1 per cent, 0.2 per cent, 0.3 per cent and 0.4 per cent of hybrid coating material. The physical and chemical properties of the graphene and copper oxide nano material are given in Table 3 and

Table 4. In Figure 4shows the TEM images of graphene nano-particles and Figure 5. The XRD analysis graphene and copper oxide is shown in Figure 6.

Table 3. Physical and chemical properties of the graphene nano-particle

\begin{tabular}{|l|c|c|}
\hline \multicolumn{1}{|c|}{ Specification } & Dimension & Unit \\
\hline Purity & $99 \%$ & \\
\hline Thermal Conductivity & 2000 & $\mathrm{~W} / \mathrm{m}-\mathrm{K}$ \\
\hline Density & 0.15 & $\mathrm{~g} / \mathrm{cm}^{3}$ \\
\hline Thickness & $5-10$ & $\mathrm{Nm}$ \\
\hline Length & $5-10$ & Micron \\
\hline Number of Layer & $4-8$ & $\mathrm{~m}^{2} / \mathrm{g}$ \\
\hline Surface Area & $200-240$ & \\
\hline
\end{tabular}

Table 4. Physical and chemical properties of the copper oxide nano-particle

\begin{tabular}{|c|c|c|}
\hline Specification & Dimension & Unit \\
\hline Purity & $99.9 \%$ & $\mathrm{~W} / \mathrm{m}-\mathrm{K}$ \\
\hline Density & 6.4 & $\mathrm{~g} / \mathrm{cm}^{3}$ \\
\hline Average particle size & $30-50$ & $\mathrm{Nm}$ \\
\hline Surface Area & $20-30$ & $\mathrm{~m}^{2} / \mathrm{g}$ \\
\hline Morphology & Near Spherical & \\
\hline
\end{tabular}

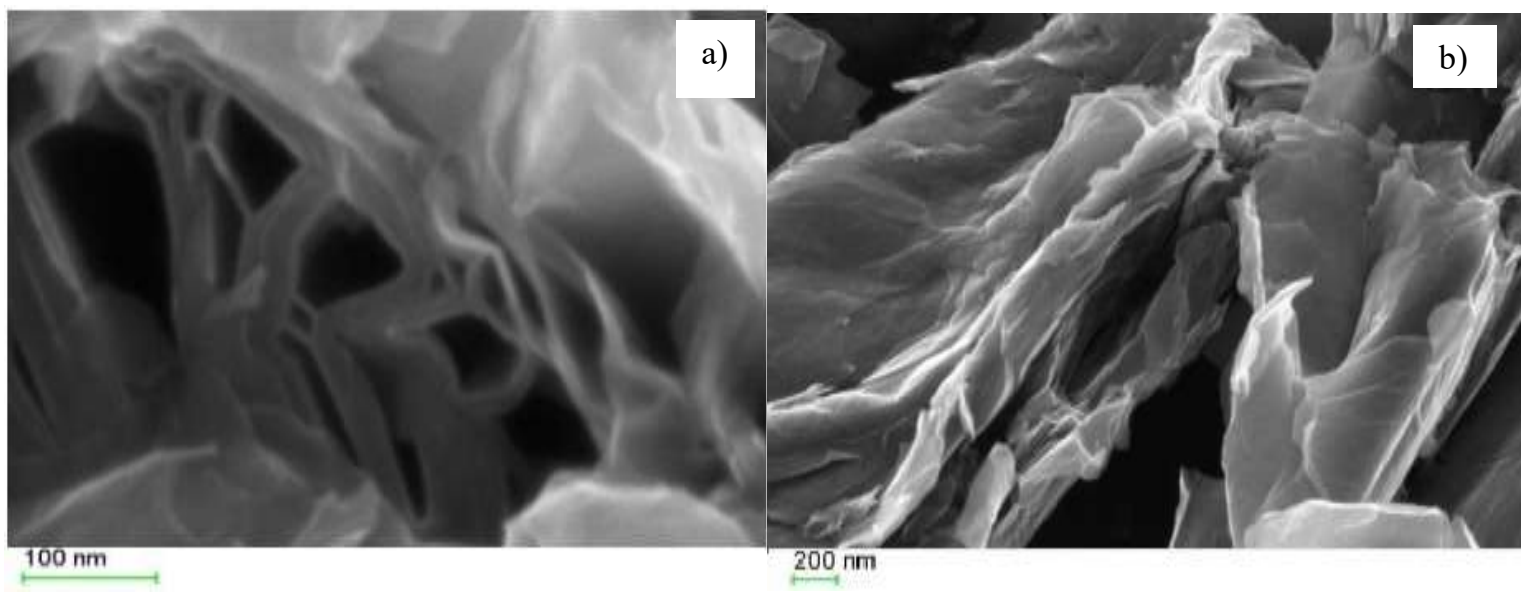

Figure 4. TEM images of graphene nano-particles a) at $100 \mathrm{~nm}$ scale, b) at $200 \mathrm{~nm}$ scale

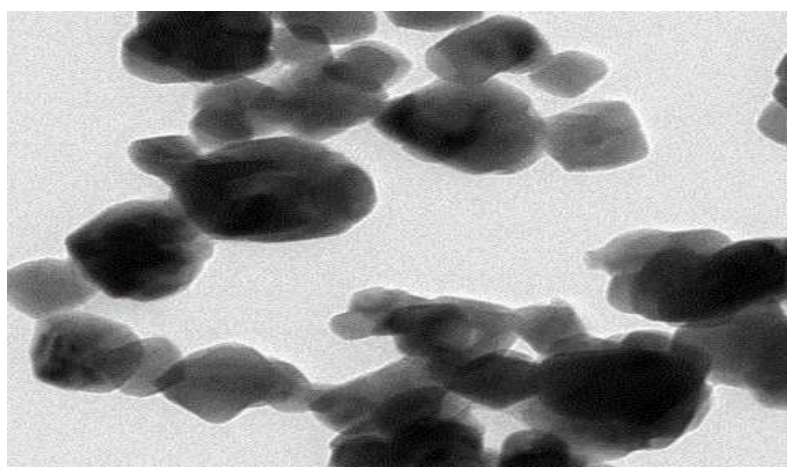

Figure 5. TEM image of copper oxide nano-particles 

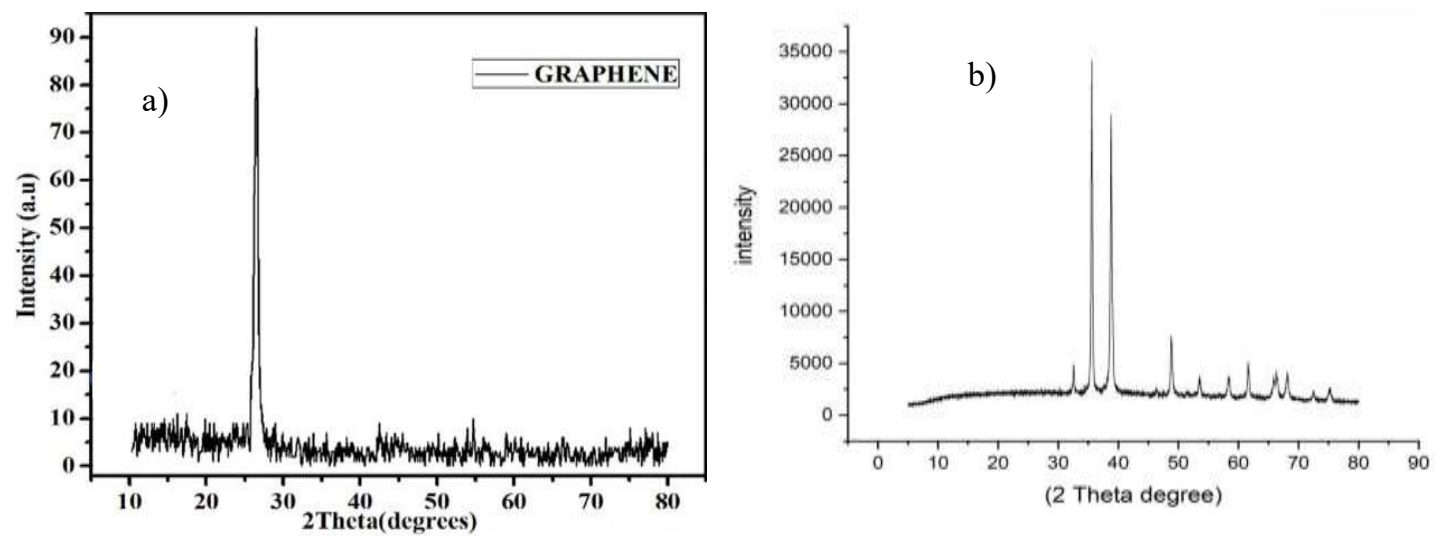

Figure 6. a) XRD analysis of graphene and b) XRD analysis of copper oxide

\section{EXPERIMENTAL METHODOLOGY}

It includes brief introduction of solar air heating system with detailed literature review. Design and fabrication of triangular solar air experimental set-up and preparation of nano-hybrid coating along with its characterization. Testing was performed in natural condition following ASHARE-93 norms. Result analysis and conclusion includes cause and effect analysis of observed data. Future scope of work also discussed. Figure 7 demonstrate schematic presentation of experimental methodology.

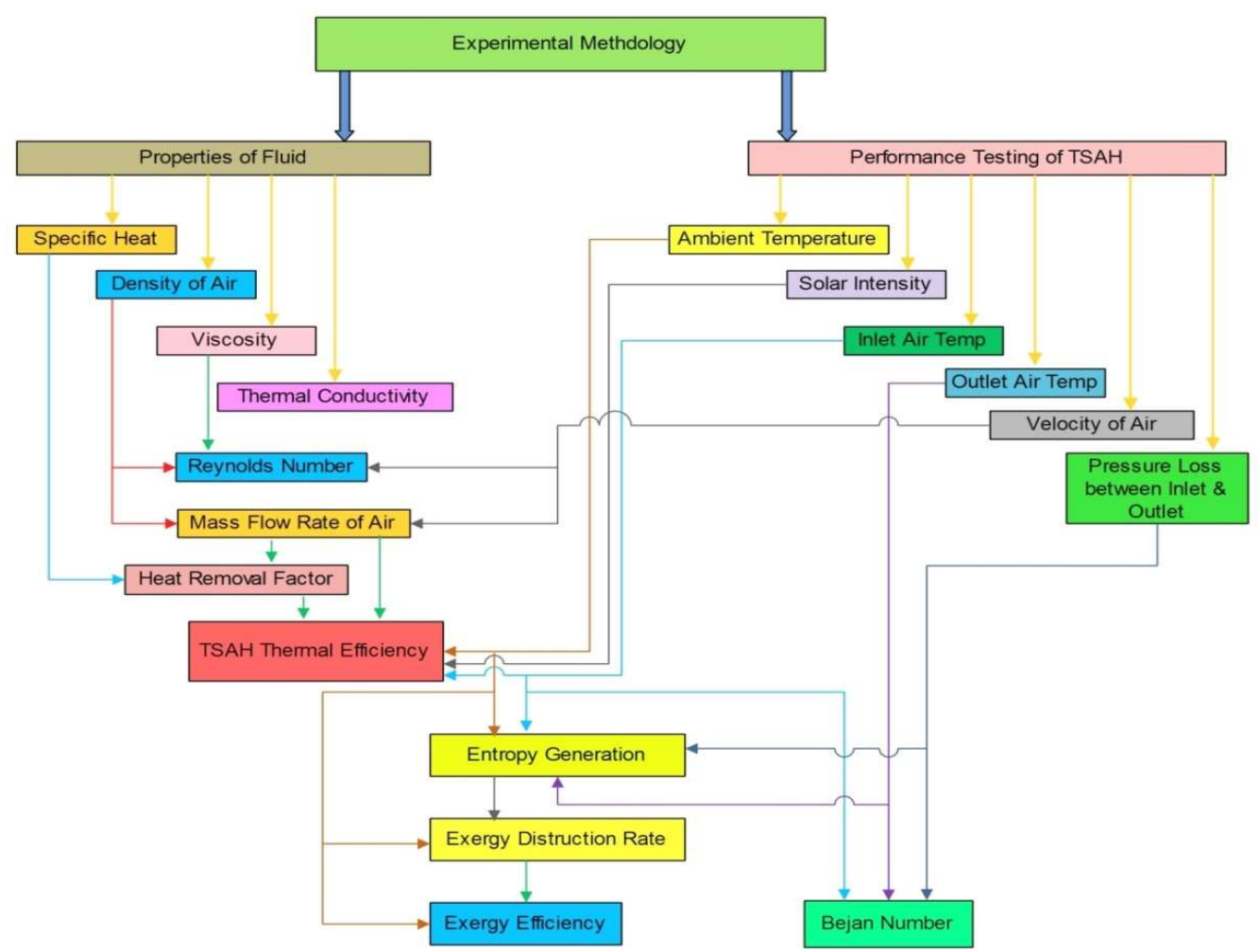

Figure 7. Experimental methodology

\section{DATA REDUCTION}

\section{Thermal Efficiency of TSAH}

In the solar heater system efficiencies are the most important parameters. These parameter determines the system performance. The useful heat rate $Q_{u}$ determined for the triangular solar air heater can be presented in form of heat energy absorbed by the system and energy lost by the system,[46]

$$
Q_{u}=A_{c} F_{r}\left[I(\tau \alpha)-U_{L}\left(T_{o}-T_{i}\right)\right]
$$


The overall heat coefficients $U_{\mathrm{L}}$ is the sum of top loss, bottom and edge loss coefficients, represented by the fallowing equation,

$$
U_{L}=U_{t}+U_{b}+U_{e}
$$

The top loss coefficients $U_{t}$ of the glass plate is calculated by the formula [47],[48]

$$
\begin{gathered}
U_{t}=\left(\frac{N}{\frac{C}{T_{p}}\left(\frac{\left(T_{p}-T_{a}\right)}{(N+f)}\right)^{e}}+\frac{1}{h_{a}}\right)^{-1}+\frac{\sigma\left(T_{p}-T_{a}\right)\left(T_{p}{ }^{2}+T_{a}{ }^{2}\right)}{\frac{1}{\epsilon_{p}+0.00591 N h_{a}}+\frac{2 N+f-1+0.133 \epsilon_{p}}{\epsilon_{g}}-N} \\
f=\left(1+0.089 h_{a}-0.01166 h_{a} \epsilon_{p}\right)(1+0.07866 N), e=0.43\left(1-\frac{100}{T_{p}}\right) \\
C=520\left[1-\left(0.000051 \beta^{2}\right)\right] \text { For } 0^{0}<\beta<70^{0}
\end{gathered}
$$

The bottom and edge heat loss coefficients are fixed for a particular setup and is given by bellow equation,[49]

$$
\begin{gathered}
U_{b}=\frac{k_{b}}{X_{b}} \\
U_{e}=U_{b}\left(\frac{A_{e}}{A_{c}}\right)
\end{gathered}
$$

$\mathrm{F}_{\mathrm{r}}$ (heat removal factor) can be determined from equation,[50]

$$
F_{R}=\frac{\dot{m} C_{\text {pair }}}{A_{c} U_{L}}\left[1-\exp \left\{\frac{-F^{\prime} U_{L} A_{p}}{\dot{m} C_{\text {pair }}}\right\}\right]
$$

The heat transfer from convection between the ambient and glass cover was calculated by the correlation [51]

$$
\begin{gathered}
h_{a}=5.7+3.8 V \\
\dot{m}=\rho_{o} A_{d} V \\
R_{e}=\frac{\rho_{o} V d}{\mu} \\
P_{r}=\dot{m} \frac{C_{\text {pair }}}{k_{a}}
\end{gathered}
$$

Nusselt number can be determined by equation[52], 


$$
N_{u}=\frac{3.66+0.0668\left(D_{h} / L\right) R_{e} P_{r}}{1+0.04\left[\left(D_{h} / L\right) R_{e} P_{r}\right]^{2 / 3}}
$$

The convective heat transfer coefficient by using the correlation of Nusselt number is determined by,

$$
\begin{gathered}
h=\frac{N_{u} k_{a}}{D_{H}} \\
F^{\prime}=\frac{h}{h+U_{L}}
\end{gathered}
$$

The first law efficiency of the TSH system is given by the ratio of heat gain to input heat energy,[53]

$$
\eta_{t h}=F_{R}\left[\tau \alpha-\frac{U_{L}\left(T_{o}-T_{i}\right)}{I}\right]
$$

\section{Exergy Efficiency of TASH}

The net exergy energy rate supplied by the solar air heater is specified by,

$$
\sum \dot{E}_{\text {inlet }}=I A\left[1-\frac{4}{3}\left(\frac{T_{a}}{T_{\text {sun }}}\right)+\frac{1}{3}\left(\frac{T_{a}}{T_{\text {sun }}}\right)^{4}\right]
$$

The sum of exergy loss rate is denoted by

$$
\sum \dot{E}_{\text {loss }}=\left(\dot{E}_{\text {opt-loss }}\right)+\left(\dot{E}_{q-l o s s}\right)+\left(\dot{E}_{f r-l o s s}\right)+\left(\dot{E}_{\text {sun }, T p-l o s s}\right)+\left(\dot{E}_{T a, T p-l o s s}\right)
$$

The external optical losses from heater is formulated by using the relation:

$$
\dot{E}_{\text {opt-loss }}=I A(1-\tau \alpha)\left[1-\frac{4}{3}\left(\frac{T_{a}}{T_{\text {sun }}}\right)+\frac{1}{3}\left(\frac{T_{a}}{T_{\text {sun }}}\right)^{4}\right]
$$

The exergy loss from SAH to surroundings is given by equation,

$$
\dot{E}_{q-l o s}=U_{L} A\left(T_{p}-T_{a}\right)\left[1-\left(\frac{T_{a}}{T_{p}}\right)\right]
$$

The frictional exergy loss of SAH is given by,

$$
\dot{E}_{f r-\text { loss }}=\frac{T_{m} m \Delta p}{\rho f T_{a}}
$$

The finite difference between the fluid causing and absorber surface the exergy destruction is given by,

$$
\dot{E}_{T a, T p-l o s s}=I A \eta_{t h} T_{a}\left[\left(\frac{1}{T_{a}}\right)-\left(\frac{1}{T_{p}}\right)\right]
$$


The exergy destruction losses due to absorption of solar intensity radiation by absorber surface is given by,

$$
\dot{E}_{\text {sun }, T p-l o s s}=I A \tau \alpha\left[1-\frac{4}{3}\left(\frac{T_{a}}{T_{\text {sun }}}\right)+\frac{1}{3}\left(\frac{T_{a}}{T_{\text {sun }}}\right)^{4}-\left(\frac{T_{a}}{T_{p}}\right)\right]
$$

Exergy efficiency of the SAH is determined by the equation,

$$
\eta_{\text {ex }}=1-\frac{\sum \dot{E}_{\text {loss }}}{\sum \dot{E}_{\text {inlet }}}
$$

\section{Analysis of Bejan Number}

The destruction of exergy rate is the sum of exergy loss rate due to temperature gradient between absorber plate and sun, exergy destruction rate caused by pressure drop, destruction of exergy rate due to air flow inside the triangular duct and the temperature gradient between the absorber plate and air, It is represented by the equations given below (27-28); [54]

$$
\begin{gathered}
\dot{E}_{d}=\dot{E}_{d, \Delta T_{s}}+\dot{E}_{d, \Delta P}+\dot{E}_{d, \Delta T_{a}} \\
\dot{E}_{d, \Delta T_{s}}=\eta_{c} I A_{c} T_{a}\left(\frac{1}{T_{p}}-\frac{1}{T_{s}}\right) \\
\dot{E}_{d, \Delta P}=\frac{\dot{m} \Delta P}{\rho} \frac{T_{a} \ln \left(\frac{T_{o}}{T_{a}}\right)}{\left(T_{o}-T_{i n}\right)} \\
\dot{E}_{d, \Delta T_{a}}=\dot{m} C_{p} T_{a}\left(\ln \frac{T_{o}}{T_{i n}}-\frac{\left(T_{o}-T_{i n}\right)}{T_{p}}\right)
\end{gathered}
$$

In addition of that exergy, overall loss coefficients of the TASH give the leakage exergy rate,

$$
\dot{E}_{l}=U_{L} A_{c}\left(T_{p}-T_{a}\right)\left(1-\frac{T_{a}}{T_{p}}\right)
$$

Then the Bejan Number is defining as,

$$
B_{e}=\frac{\dot{S}_{g e n, \Delta T}}{\dot{S}_{g e n, \Delta T}+\dot{S}_{g e n, \Delta p}}
$$

Therefore the entropy generation rate depends on the formula[55]

$$
\dot{S}_{g e n}=\frac{\dot{W}_{l}}{T_{a}}=\frac{\dot{E}_{d} \dot{E}_{l}}{T_{a}}
$$

where, $\dot{\mathrm{S}}_{\mathrm{gen}, \Delta \mathrm{T}}$ is entropy generation due to temperature and $\dot{\mathrm{S}}_{\mathrm{gen}, \Delta \mathrm{p}}$ is entropy generation due to pressure drop. 


$$
\dot{S}_{g e n, \Delta T} T_{a}=\eta_{c} I A_{c} T_{a}\left(\frac{1}{T_{p}}-\frac{1}{T_{s}}\right)+\dot{m} C_{p} T_{a}\left(\ln \frac{T_{o}}{T_{i n}}-\frac{\left(T_{o}-T_{i n}\right)}{T_{p}}\right)+U_{L} A_{c}\left(T_{p}-T_{a}\right)\left(1-\frac{T_{a}}{T_{p}}\right)
$$

\section{Experimental Uncertainty Analysis}

For the authentic and faithful data measurements of the experimental parameters, the uncertainty examination is necessary to estimate the improvement in experimental measurement. In this study, measured parameters have been divided into the two categories. The first type parameters depend on exergy efficiency, thermal efficiency and entropy generation. We measure the second type parameters like solar radiation, temperature and the mass flow rate of air. The uncertainty analysis is calculated by the root square method and is given by equation,[56]

$$
\delta_{\eta_{c}}=\left[\sum_{i=1}^{n}\left(\frac{\partial \eta_{c}}{\partial x_{i}} \delta x_{i}\right)^{2}\right]^{1 / 2}
$$

Where $x_{i}$ is the input data measured by the instrument, $\delta x_{i}$ is the uncertainty analysis and $\delta_{\eta_{c}}$ is the efficiency uncertainty of the TSAH. Thermal efficiency equation based on the mathematical expression,

$$
\begin{gathered}
\frac{\partial \eta_{\text {ex }}}{\eta_{\text {ex }}}=\left[\left(\frac{\partial T_{s}}{T_{s}}\right)^{2}+\left(\frac{\partial\left(T_{s}-T_{a}\right)}{\left(T_{s}-T_{a}\right)}\right)^{2}+\left(\frac{\partial \dot{E}_{x, \text { dest }}}{\dot{E}_{x, \text { dest }}}\right)^{2}+\left(\frac{\partial \dot{Q}_{s}}{\dot{Q}_{s}}\right)^{2}\right]^{1 / 2} \\
\frac{\partial \eta_{c}}{\eta_{c}}=\left[\left(\frac{\partial T^{2}}{I}\right)^{2}+\left(\frac{\partial\left(T_{i}-T_{a}\right)}{\left(T_{i}-T_{a}\right)}\right)^{2}+\left(\frac{\partial(\tau \alpha)}{(\tau \alpha)}\right)^{2}+\left(\frac{\partial U_{L}}{U_{L}}\right)^{2}+\left(\frac{\partial F_{R}}{F_{R}}\right)^{2}\right]^{1 / 2} \\
\frac{\partial S_{\text {gen }}}{S_{\text {gen }}}=\left[\left(\frac{\partial \dot{E}_{x, \text { dest }}}{\dot{E}_{x, \text { dest }}}\right)^{2}+\left(\frac{\partial T_{a}}{T_{a}}\right)^{2}\right]^{1 / 2}
\end{gathered}
$$

For the measurement of uncertainty second type parameter, we can use the error estimation for dependent parameters and its calculated by the following relation:

$$
W=\left[\left(x_{1}\right)^{2}+\left(x_{2}\right)^{2}+\left(x_{3}\right)^{2}+\cdots+\left(x_{n}\right)^{2}\right]^{1 / 2}
$$

Uncertainties in different calculated parameters for the present experimental work are presented in Table 5.

Table 5. Uncertainties analysis of parameters

\begin{tabular}{|c|c|}
\hline Variable & Uncertainties Value(\%) \\
\hline Air Inlet Temperature & \pm 0.16 \\
\hline Air outlet Temperature & \pm 0.16 \\
\hline Mass flow rate of Air & \pm 2.5 \\
\hline Velocity of Air & \pm 3.4 \\
\hline Density of Air & \pm 0.67 \\
\hline Heat Transfer Coefficient & \pm 5.2 \\
\hline Reynolds Number & \pm 1.88 \\
\hline Heat energy received & \pm 4.2 \\
\hline Thermal Efficiency & \pm 3.25 \\
\hline Exergy Efficiency & \pm 1.45 \\
\hline Entropy Generation & \pm 2.65 \\
\hline
\end{tabular}




\section{RESULT AND DISCUSSION}

In this section, we have investigated the effect of absorber plate coating of different percentage graphene and copper oxide nano-particles on the thermal efficiency and exergy analysis. For the experimental investigation of the TSAH we have follow ASHRAE standards. To maintain the steady-state condition, 10 min time intervals taken for every set of experimental observations. These observations have a five-set of observations to minimize the error in observations. Performance of TSAH can be defined by parameters: the thermal efficiency, exergy efficiency and entropy generation. In Figure 8, shows the variation of thermal efficiency of TSAH with respect to mass flow rate for varying concentration of selective coating. For each set of absorber plate coating material at constant solar intensity $\mathrm{I}=800 \mathrm{~W} / \mathrm{m}^{2}$ and ambient temperature $\mathrm{Ta}=289 \mathrm{~K}$. The thermal efficiency increases with the air mass flow rate and maximum efficiency can be found at $0.01847 \mathrm{~kg} / \mathrm{s}$. The maximum thermal efficiency is $69.42 \%, 70.9 \%, 73.19 \%$ and $72.36 \%$ for different percentage of absorber coating at the mass flow rate of $0.01809 \mathrm{~kg} / \mathrm{s}$. It is observed that the average thermal efficiency for $0.3 \%$ graphene/CuO-black paint is higher by $4.91 \%$ then the $0.1 \%$ graphene/CuO-black paint considering the maximum mass flow rate. In the experimental study, we find it for every case the thermal efficiency increases with increasing mass flow rate of air. Therefore, thermal energy is transferred to the air by increasing the effect of turbulence inside the test section at higher mass flow rates and it also decreases the temperature of the absorber plate. Hence it reduces the heat loss to the surrounding, which provides higher thermal efficiency.

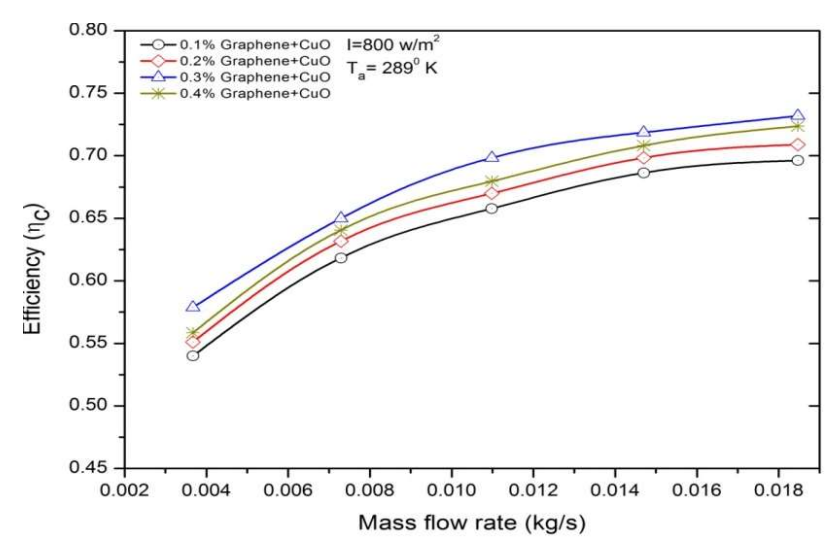

Figure 8. Thermal efficiency vs. mass flow rate for different absorber plate coating

In Figure 9, demonstrates the variation of TSAH exergy efficiency vs. mass flow rate at different absorber plate coating at constant solar intensity $\mathrm{I}=800 \mathrm{~W} / \mathrm{m} 2$ and ambient temperature $\mathrm{Ta}=289 \mathrm{~K}$. Exergy efficiency as exhibited in graph (Figure 9) is decreases with mass flow rate. With higher concentration of coating, energy utilization factor enhances the exergy efficiency. Increase in mass flow rate enhances the pressure drop and leads to lower exergy efficiency in all the cases. The effective exergy efficiency is increases at $0.1 \%$ graphene/CuO-black paint to $0.3 \%$ graphene/CuO-black paint for same mass flow rate. Also further increases the mass flow rate reduces rate of energy absorption and excess in pressure drop resulted in lower exergy efficiency for all cases of incremental mass flow rate. The exergy efficiency is a function of mass flow rate. If the mass flow rate increases then exergy efficiency is decreases due to fact that decreases in outlet temperature, exergy losses and higher the pumping power. Thus the exergy efficiency fallows the declining pattern.

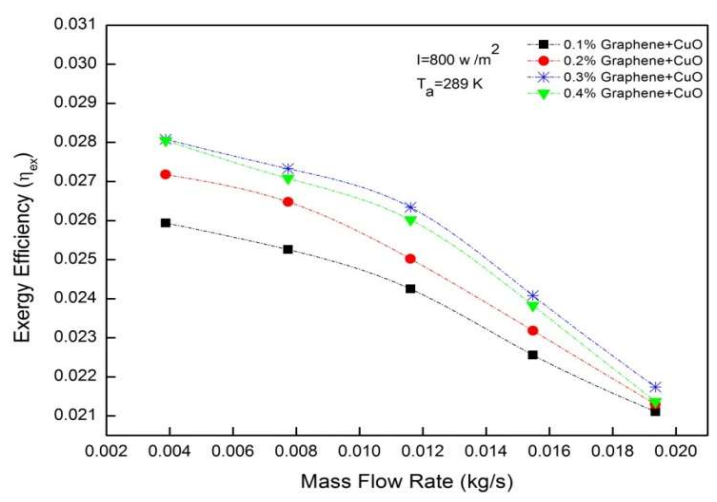

Figure 9. Exergy efficiency vs. mass flow rate for different absorber plate coating 
In Figure 10, shows the behaviour of entropy-generation vs. mass flow rate at increasing concentration of absorber plate coating at fixed solar irradiance $\mathrm{I}=800 \mathrm{~W} / \mathrm{m}^{2}$. For the design and further improvement of the TSAH entropy generation analysis is cardinal. For any thermal system, minimization of entropy generation is the prime objective to enhance exergy efficiency. As the air mass flow rate increase, it also increases the entropy generation. Entropy generation represents the temperature difference of heat transfer rate and pressure drop between inlet and outlet section. The entropy generation is lower for $0.3 \%$ graphene/CuO-black paint and higher for $0.1 \%$ graphene/CuO-black paint for the same mass flow rate because the nanomaterial coating on absorber plate which increases absorption surface area. According to the equation (18) exergy loss is directly proportional to entropy generation rate because of loss of heat energy at higher mass flow rate. For increasing mass flow rate entropy generation also increases, thus exergy efficiency deceases because of entropy generation gives an adverse effect on exergy efficiency. It can be concluded that TSAH system performs better for $0.3 \%$ graphene/CuO-black paint coating.

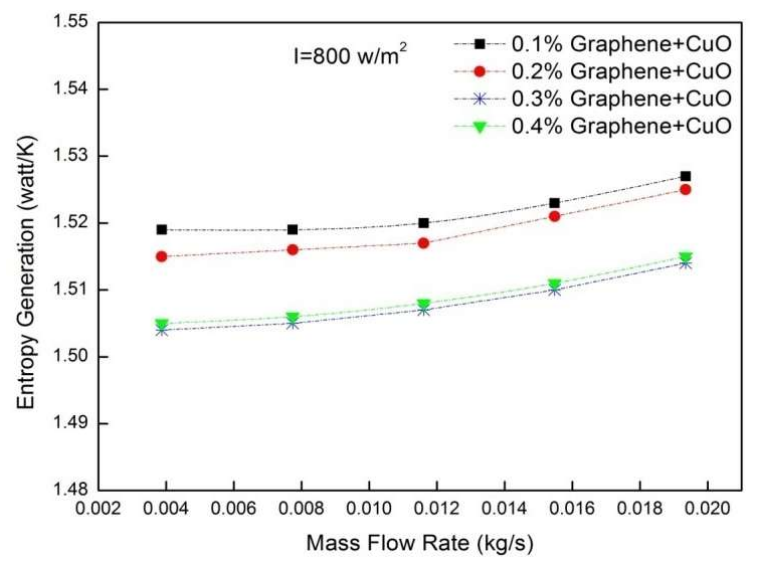

Figure 10. Entropy generation vs. mass flow rate for different absorber plate coating

In Figure 11, demonstrate the thermo-behavioral change of exergy efficiency vs. solar intensity at a fixed mass rate $0.00387 \mathrm{~kg} / \mathrm{s}$. As solar intensity increases, the exergy efficiency is decreased and the exergy efficiency depends on the sum of exergy destruction rate and temperature difference between the input and output of the system. As the solar intensity increases which increase in temperature of the absorber plate which is associated with the exergy destruction losses due to absorption surface. This causes the exergy efficiency is decreasing throughout the TSAH.

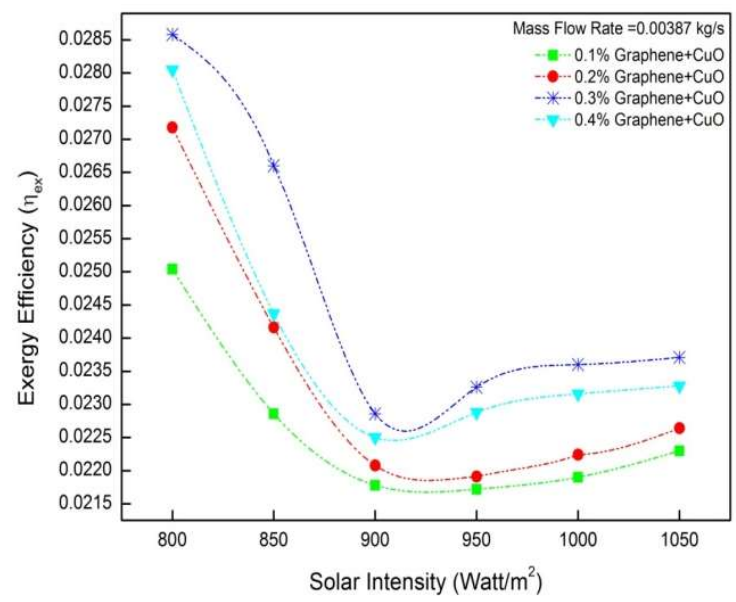

Figure 11. Variation of exergy efficiency vs. solar intensity

In Figure 12, shows the behavior of exergy energy vs. solar intensity. As the solar intensity increases then exergy energy is also increases because the exergy destruction rate occurring due to higher temperature difference between sun and absorber plate. It enhances exergy losses. Due to the resulting increase in absorber Plate temperature, this loss is proportional to rising solar intensity. It is observed that the exergy destruction is due to temperature difference between the absorber plate and flowing air. Now it can be inferred that solar intensity augments the exergy destruction rate. 


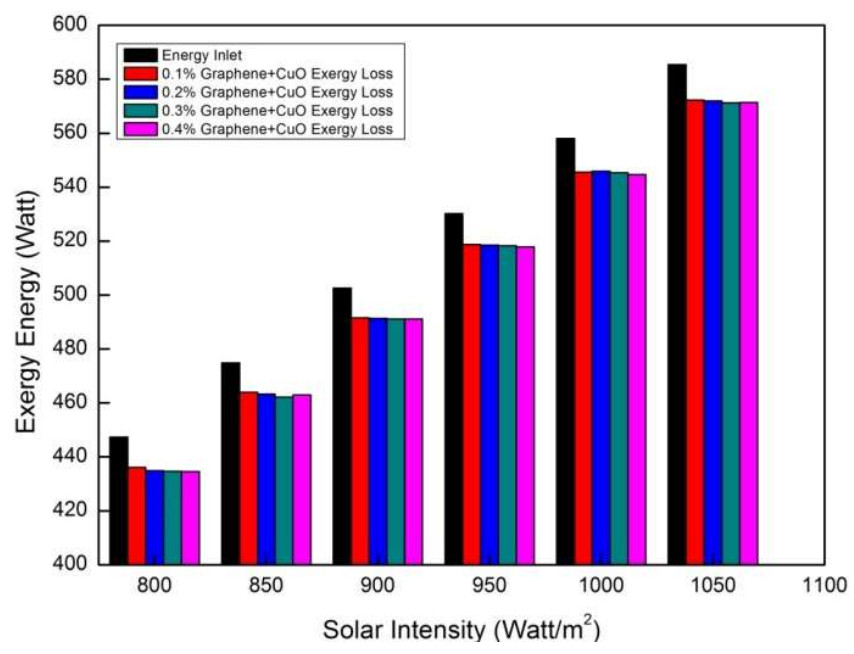

Figure 12. Variation energy inlet vs. solar intensity

In Figure 13, the variation of Bejan number Vs mass flow rate at varying coating concentration of absorber plate at fixed solar irradiance $\mathrm{I}=900 \mathrm{w} / \mathrm{m}^{2}$ and ambient temperature $\mathrm{Ta}=292 \mathrm{~K}$. The phenomena of exergy efficiency and entropy generation rate can be precisely explained by the Bejan number [51]-[57]-[58],It varies with mass flow rate and variation of specific nature of graphene and copper oxide coating on the absorber plate. As the air mass flow rate increases, it also decreases the Bejan number. According to Bejan number equation (1), heat transfer to the absorber plate to air and combine entropy generation takes place because of air flowing inside the TSAH and the temperature difference between absorber plate and air. At the higher air mass flow rate the contribution of permanent heat transfer becomes considerable, which results in reduction of the Bejan number. The value of Bejan number for $0.3 \%$ graphene $/ \mathrm{CuO}$-black paint is higher with respect to $0.1 \%, 0.2 \%$ and $0.4 \%$ graphene/CuO-black paint because of superior thermal conductivity and convective heat transfer coefficients of the absorber plate coating.

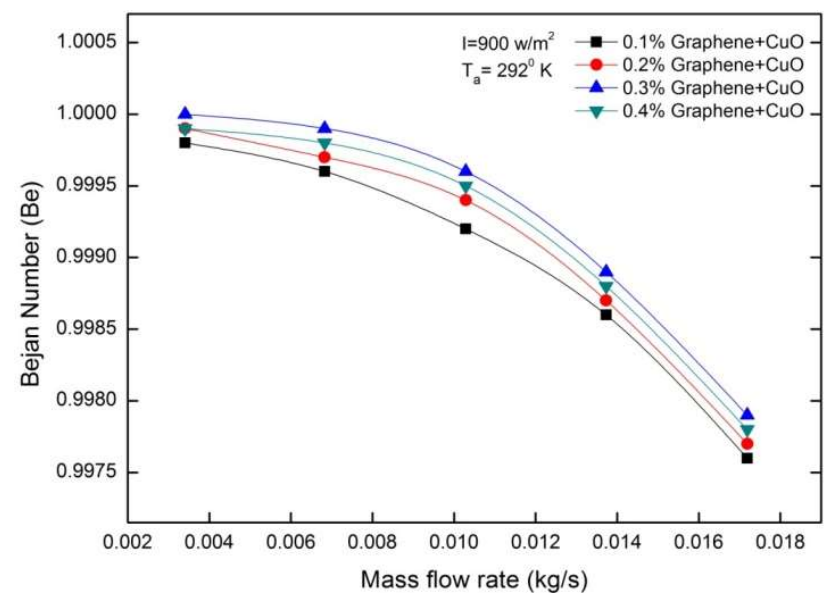

Figure 13. Bejan number vs. mass flow rate for increasing concentration of absorber coating

In Figure 14, shows the effect of increasing absorber surface concentration on ambient temperature and thermal efficiency at fixed air flow rate $\mathrm{m}=0.007294 \mathrm{~kg} / \mathrm{s}$. As the solar intensity increases, correspondingly the ambient temperature of air also increases and the thermal efficiency decreases. This reflects in reduction of thermal efficiency of the TSAH. Due to absence of any obstruction inside TSAH, exposure time between the air and surface of the absorber plate is less because of lesser contact of air, so it will decrease heat transfer rate. Therefore, the inlet temperature of air and solar intensity is increased and the thermal efficiency in every case is deceases.

In Figure 15, shows the variation of Nusselt number and friction factor of air vs. Reynolds number at different absorber plate coating of TSAH. As the Reynolds number increases, it also increases the Nusselt number and decreases the friction factor. According to the Hausen equation of Nusselt number (13), shows the heat transfer at a boundary layer near the absorber plate. If Reynolds number increases, it produces air turbulence inside triangular section which improves the main flow interaction to the absorber plate and increases heat transfer rate. Thus it can be concluded that the Reynolds number strongly affects the Nusselt number. The friction factor is inversely proportional to the Reynolds 
number. The friction factor decreases with the Reynolds number. Friction factor interrupting the boundary layer and reducing loss of flow separation.

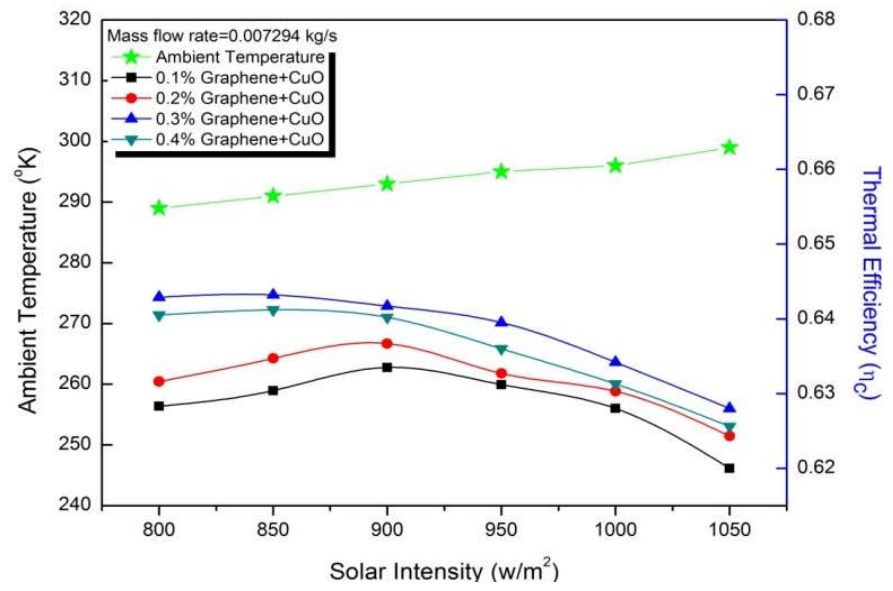

Figure 14. Ambient temperature and efficiency vs. flow rate of air for increasing absorber surface coating

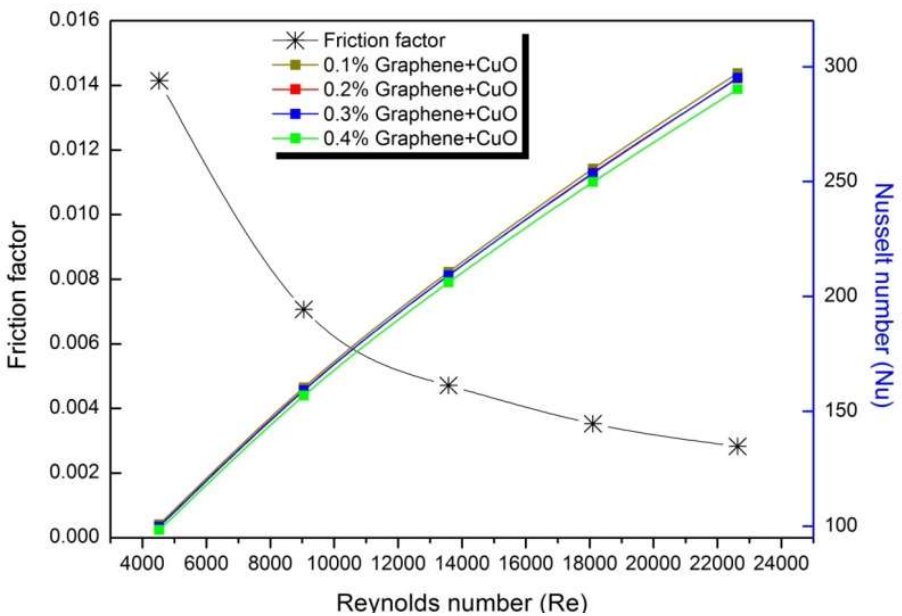

Figure 15. Nusselt number and friction factor vs. Reynolds number for increasing absorber surface concentration

In Figure 16, shows the variation of outlet temperature and thermal efficiency vs. air velocity. At the air velocity increases outlet temperature reduces because heat transfer from absorber plate to air is decreases but thermal efficiency is increases.

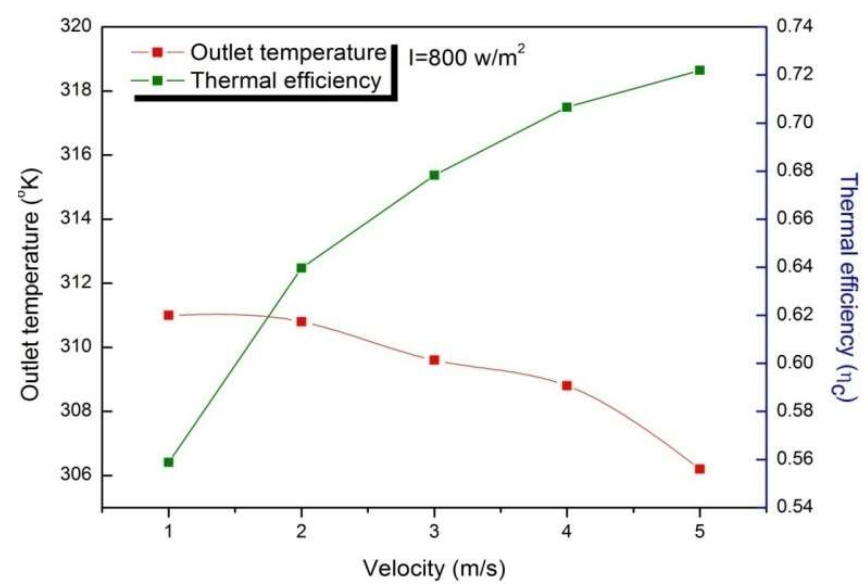

Figure 16. Outlet temperature and thermal efficiency vs. air velocity 
In Figure 17, shows the variation of air temperature vs. length of TSAH. As the triangular section length increases, the air temperature increases. At the entrance, there has been a higher temperature gradient between the absorber plate and inlet air. If length of the solar air heater increases the temperature gradient reduces due to heat transfer from the absorber plate to air which result increases the air temperature. The maximum increment in air temperature at $0.3 \%$ graphene $/ \mathrm{CuO}$-black paint whereas the minimum increment in $0.1 \%$ graphene/CuO-black paint absorber plate.

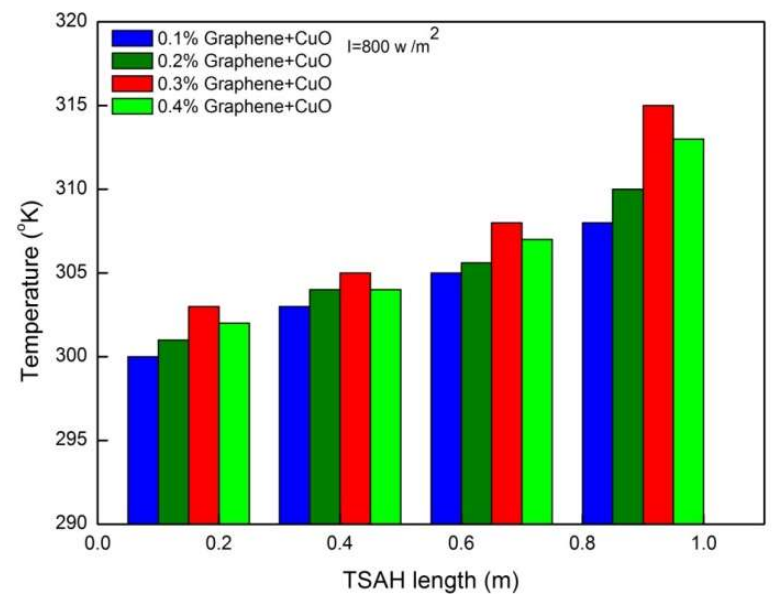

Figure 17. Variation of air temperature vs. length of TSAH

\section{CONCLUSIONS}

In the presented experimental study, the experiment was carried out for the TSAH to see the effect on thermal efficiency, exergy efficiency, entropy generation and Bejan number. Based on the input parameters considered and experimental result obtained with respect to the graphene and copper oxide nano-particle into black paint coating on the absorber plate. These are four types $0.1 \%, 0.2 \%, 0.3 \%$ and $0.4 \%$ graphene/CuO-black paint. The results can be concluded as follows:

- For absorber plate coating with $0.3 \%$ graphene/CuO-black paintgives the higher thermal efficiency in comparison with other type of coating configurations. The increment of average thermal efficiency $(0.3 \%)$ is $3.58 \%, 2.35 \%$ and 1.344 for $0.1 \%, 0.2 \%$ and $0.4 \%$ graphene/CuO-black paint respectively at solar intensity $\mathrm{I}=800 \mathrm{w} / \mathrm{m}^{2}$.

- The improved efficiency of Exergy for $0.3 \%$ graphene/CuO-black paint has been observed. An improvement in average energy efficiency of 0.3 percent graphene/CuO-Black paint is 0.169 percent, while solar intensity $\mathrm{I}=800 \mathrm{~W} / \mathrm{m}^{2}$ is 0.1 percent graphene/CuO-Black paint.

- The optimum magnitude of exergy efficiency obtained for a air mass rate of $0.00387 \mathrm{~kg} / \mathrm{s}$. Further increase in mass flow rate brings adverse impact on exergy efficiency for all cases of graphene/CuO-black paint coating.

- Entropy generation is more than $0.1 \%$ graphene/CuO-black paint coating and a minimum $0.3 \%$ graphene/CuO-black paint coating.

- Bejan number gives higher value for $0.3 \%$ graphene/CuO-black paintis0.999, which is the highest for all cessations due to this fact a TSAH device gives better output for $0.3 \%$ graphene/CuO-black paint and is highly effective in transforming solar energy into useful work.

- The ambient temperature ranges from $287 \mathrm{~K}$ to $298 \mathrm{~K}$ on Feb16-18, 2020 and during the experiment day the solar intensity ranged from 800 to $1050 \mathrm{w} / \mathrm{m}^{2}$.

- Reynolds number and heat transfer coefficients of air is increases with respect to mass flow rate. The Reynolds number $\left(4500 \leq R_{e} \leq 22700\right)$ varies for the fixed selective coating on absorber plate and mass flow rate.

In the presented experimental research, it was observed that selective coatings and modified design play a dominant role in enhancing solar air heating system thermal and exergetic efficiency.

There is further scope of research in modifications of designs, selective coating designs, application of hybrid PCM and design of obstructions (inserts) to achieve higher temperature rise of working fluid. 


\title{
CONFLICT OF INTERESTS
}

An author declares that they have no conflict of interests with any organization or persons.

\section{NOMENCLATURE}

L

W

I

$\mathrm{V}$

$\mathrm{D}_{\mathrm{H}}$

$\mathrm{m}$

$\mathrm{A}_{\mathrm{e}}$

$\mathrm{A}_{\mathrm{c}}$

$\mathrm{A}_{\mathrm{p}}$

$\mathrm{T}_{\mathrm{p}}$

$\mathrm{T}_{\text {sur }}$

$\mathrm{T}_{\mathrm{i}}$

$\mathrm{T}_{\mathrm{a}}$

$\mathrm{T}_{\mathrm{s}}$

$\mathrm{T}_{\mathrm{o}}$

$\mathrm{U}_{\mathrm{L}}$

$\mathrm{U}_{\mathrm{t}}$

$\mathrm{Qu}_{\mathrm{u}}$

$\mathrm{F}_{\mathrm{r}}$

$\varepsilon_{\mathrm{p},} \varepsilon_{\mathrm{g}}$

$\mathrm{k}_{\mathrm{a}}$

$\mathrm{h}_{\mathrm{a}}$

Pr

Re

$\mathrm{Nu}$

$\mathrm{X}_{\mathrm{b}}$

Abbreviations

AC

CAS

CFD

SAH

TEM

TSAH

XRD

FPSC
Length of triangular section

width of triangular section

solar intensity

velocity of air

hydraulic diameter of triangular section

mass flow rate of air

area of edge surface

area of glazing plate

area of absorber plates

absorber plate temperature

surrounding temperature

air inlet temperature

ambient temperature

sun temperature

air outlet temperature

overall heat coefficients

top loss coefficients

useful heat

heat removal factor

emissivity of absorber plate and glass cover

thermal conductivity of back insulation

heat transfer coefficients of air

Prandtl Number

Reynolds Number

Nusselt Number

back insulation thickness

Greek Symbol

$\begin{array}{ll}\alpha & \text { absorptivity } \\ \beta & \text { tilt angle } \\ \mu & \text { viscosity of air } \\ \tau & \text { transmitivity } \\ \rho_{o} & \text { density of air }\end{array}$

\author{
Alternating Current \\ Chemical Abstracts Service \\ Computational Fluid Dynamics \\ Solar air heater \\ Transmission electron microscopy \\ Triangular solar air heater \\ X-ray diffraction \\ Flat plate solar collector
}

\section{REFERENCES}

[1] Öztürk HH. Experimental evaluation of energy and exergy efficiency of a seasonal latent heat storage system for greenhouse heating. Energy Conversion and Management 2005;46:1523-42. https://doi.org/10.1016/j.enconman.2004.07.001.

[2] Tyagi SK, Wang S, Singhal MK, Kaushik SC, Park SR. Exergy analysis and parametric study of concentrating type solar collectors. International Journal of Thermal Sciences 2007;46:1304-10. https://doi.org/10.1016/j.ijthermalsci.2006.11.010.

[3] Jafarkazemi F, Ahmadifard E. Energetic and exergetic evaluation of flat plate solar collectors. Renewable Energy 2013;56:55-63. https://doi.org/10.1016/j.renene.2012.10.031.

[4] El Nady J, Kashyout AB, Ebrahim Sh, Soliman MB. Nanoparticles Ni electroplating and black paint for solar collector applications. Alexandria Engineering Journal 2016;55:723-9. https://doi.org/10.1016/j.aej.2015.12.029. 
[5] Öztürk HH. Experimental evaluation of energy and exergy efficiency of a seasonal latent heat storage system for greenhouse heating. Energy Conversion and Management 2005;46:1523-42. https://doi.org/10.1016/j.enconman.2004.07.001.

[6] Gupta MK, Kaushik SC. Exergetic performance evaluation and parametric studies of solar air heater. Energy 2008;33:1691-702. https://doi.org/10.1016/j.energy.2008.05.010.

[7] Singh PK, Anoop KB, Sundararajan T, Das SK. Entropy generation due to flow and heat transfer in nanofluids. International Journal of Heat and Mass Transfer 2010;53:4757-67. https://doi.org/10.1016/j.ijheatmasstransfer.2010.06.016.

[8] Akpinar EK, Koçyiğit F. Energy and exergy analysis of a new flat-plate solar air heater having different obstacles on absorber plates. Applied Energy 2010;87:3438-50. https://doi.org/10.1016/j.apenergy.2010.05.017.

[9] Ching YC, Öztop HF, Rahman MM, Islam MR, Ahsan A. Finite element simulation of mixed convection heat and mass transfer in a right triangular enclosure. International Communications in Heat and Mass Transfer 2012;39:689-96. https://doi.org/10.1016/j.icheatmasstransfer.2012.03.016.

[10] Sriromreun P, Thianpong C, Promvonge P. Experimental and numerical study on heat transfer enhancement in a channel with Z-shaped baffles. International Communications in Heat and Mass Transfer 2012;39:945-52. https://doi.org/10.1016/j.icheatmasstransfer.2012.05.016.

[11] Malvandi A, Ganji DD, Hedayati F, Rad E. Yousefi. An analytical study on entropy generation of nanofluids over a flat plate. Alexandria Engineering Journal 2013;52:595-604. https://doi.org/10.1016/j.aej.2013.09.002.

[12] Parvin S, Nasrin R, Alim MA. Heat transfer and entropy generation through nanofluid filled direct absorption solar collector. International Journal of Heat and Mass Transfer 2014;71:386-95. https://doi.org/10.1016/j.ijheatmasstransfer.2013.12.043.

[13] Mahian O, Kianifar A, Sahin AZ, Wongwises S. Entropy generation during Al2O3/water nanofluid flow in a solar collector: Effects of tube roughness, nanoparticle size, and different thermophysical models. International Journal of Heat and Mass Transfer 2014;78:64-75. https://doi.org/10.1016/j.ijheatmasstransfer.2014.06.051.

[14] Skullong S, Kwankaomeng S, Thianpong C, Promvonge P. Thermal performance of turbulent flow in a solar air heater channel with rib-groove turbulators. International Communications in Heat and Mass Transfer 2014;50:34-43. https://doi.org/10.1016/j.icheatmasstransfer.2013.11.001.

[15] Shojaeizadeh E, Veysi F, Kamandi A. Exergy efficiency investigation and optimization of an Al2O3-water nanofluid based Flat-plate solar collector. Energy and Buildings 2015;101:12-23. https://doi.org/10.1016/j.enbuild.2015.04.048.

[16] Bahrehmand D, Ameri M, Gholampour M. Energy and exergy analysis of different solar air collector systems with forced convection. Renewable Energy 2015;83:1119-30. https://doi.org/10.1016/j.renene.2015.03.009.

[17] Verma SK, Tiwari AK, Chauhan DS. Performance augmentation in flat plate solar collector using $\mathrm{MgO} / \mathrm{water}$ nanofluid. Energy Conversion and 2016;124:607-17. https://doi.org/10.1016/j.enconman.2016.07.007.

[18] Kalaiarasi G, Velraj R, Swami MV. Experimental energy and exergy analysis of a flat plate solar air heater with a new design of integrated sensible heat storage. Energy 2016;111:609-19. https://doi.org/10.1016/j.energy.2016.05.110.

[19] Zhu T, Diao Y, Zhao Y, Ma C. Performance evaluation of a novel flat-plate solar air collector with micro-heat pipe arrays (MHPA). Applied Thermal Engineering 2017;118:1-16. https://doi.org/10.1016/j.applthermaleng.2017.02.076.

[20] Gill RS, Hans VS, Singh S. Investigations on thermo-hydraulic performance of broken arc rib in a rectangular duct of solar air heater. International Communications in Heat and Mass Transfer 2017;88:20-7. https://doi.org/10.1016/j.icheatmasstransfer.2017.07.024.

[21] Ghiami A, Ghiami S. Comparative study based on energy and exergy analyses of a baffled solar air heater with latent storage collector. Applied Thermal Engineering 2018;133:797-808. https://doi.org/10.1016/j.applthermaleng.2017.11.111.

[22] Abuşka M. Energy and exergy analysis of solar air heater having new design absorber plate with conical surface. Applied Thermal Engineering 2018;131:115-24. https://doi.org/10.1016/j.applthermaleng.2017.11.129.

[23] Kilic M. A numerical analysis of transpiration cooling as an air cooling mechanism. Heat Mass Transfer 2018;54:3647-62. https://doi.org/10.1007/s00231-018-2391-6.

[24] Kilic M. Numerical investigation of heat transfer from a porous plate with transpiration cooling. Journal of Thermal Engineering 2018;4:1632-47. https://doi.org/DOI: 10.18186/journal-of-thermal-engineering.362048.

[25] Mortazavi A, Ameri M. Conventional and advanced exergy analysis of solar flat plate air collectors. Energy 2018;142:277-88. https://doi.org/10.1016/j.energy.2017.10.035.

[26] Kilic M, Abdulvahitoglu A. Numerical investigation of heat transfer at a rectangular channel with combined effect of nanofluids and swirling jets in a vehicle radiator. Thermal Science 2018:294-294. https://doi.org/DOI: 10.2298/TSCI180816294K.

[27] Kilic M, Ali H. Numerical investigation of combined effect of nanofluids and multiple impinging jets on heat 
transfer. Thermal Science 2018:94-94. https://doi.org/DOI: 10.2298/TSCI171204094K.

[28] Kumar A, Layek A. Energetic and exergetic performance evaluation of solar air heater with twisted rib roughness on absorber plate. Journal of Cleaner Production 2019;232:617-28. https://doi.org/10.1016/j.jclepro.2019.05.363.

[29] Abdelkader TK, Zhang Y, Gaballah ES, Wang S, Wan Q, Fan Q. Energy and exergy analysis of a flat-plate solar air heater coated with carbon nanotubes and cupric oxide nanoparticles embedded in black paint. Journal of Cleaner Production 2020;250:119501. https://doi.org/10.1016/j.jclepro.2019.119501.

[30] Nidhul K, Kumar S, Yadav AK, Anish S. Enhanced thermo-hydraulic performance in a V-ribbed triangular duct solar air heater: CFD and exergy analysis. Energy 2020;200:117448. https://doi.org/10.1016/j.energy.2020.117448.

[31] Šest E, Dražič G, Genorio B, Jerman I. Graphene nanoplatelets as an anticorrosion additive for solar absorber coatings. Solar Energy Materials and Solar Cells 2018;176:19-29. https://doi.org/10.1016/j.solmat.2017.11.016.

[32] Wang D, Liu J, Liu Y, Wang Y, Li B, Liu J. Evaluation of the performance of an improved solar air heater with "S" shaped ribs with gap. Solar Energy 2020;195:89-101. https://doi.org/10.1016/j.solener.2019.11.034.

[33] Abo-Elfadl S, Hassan H, El-Dosoky MF. Study of the performance of double pass solar air heater of a new designed absorber: An experimental work. Solar Energy 2020;198:479-89. https://doi.org/10.1016/j.solener.2020.01.091.

[34] Hassan H, Abo-Elfadl S, El-Dosoky MF. An experimental investigation of the performance of new design of solar air heater (tubular). Renewable Energy 2020;151:1055-66. https://doi.org/10.1016/j.renene.2019.11.112.

[35] R. Kumar, S. K. Verma, and V. K. Sharma R. K. Performance Analysis of Triangular Air Heating System Using Solar Energy n.d.:13-6. https://doi.org/doi: COMET201913.

[36] Kumar R, Verma SK, Sharma VK. Performance enhancement analysis of triangular solar air heater coated with nanomaterial embedded in black paint. Materials Today: Proceedings 2020;26:2528-32. https://doi.org/10.1016/j.matpr.2020.02.538.

[37] Bensaci C-E, Moummi A, Sanchez de la Flor FJ, Rodriguez Jara EA, Rincon-Casado A, Ruiz-Pardo A. Numerical and experimental study of the heat transfer and hydraulic performance of solar air heaters with different baffle positions. Renewable Energy 2020;155:1231-44. https://doi.org/10.1016/j.renene.2020.04.017.

[38] Abdullah AS, Amro MI, Younes MM, Omara ZM, Kabeel AE, Essa FA. Experimental investigation of single pass solar air heater with reflectors and turbulators. Alexandria Engineering Journal 2020;59:579-87. https://doi.org/10.1016/j.aej.2020.02.004.

[39] Akhbari M, Rahimi A, Hatamipour MS. Modeling and experimental study of a triangular channel solar air $\begin{array}{llll}\text { heater. } & \text { Applied } & \text { Thermal } & \text { Engineering } 170: 114902 .\end{array}$ https://doi.org/10.1016/j.applthermaleng.2020.114902.

[40] Arunkumar HS, Vasudeva Karanth K, Kumar S. Review on the design modifications of a solar air heater for improvement in the thermal performance. Sustainable Energy Technologies and Assessments 2020;39:100685. https://doi.org/10.1016/j.seta.2020.100685.

[41] Darici S, Kilic A. Comparative study on the performances of solar air collectors with trapezoidal corrugated and flat absorber plates. Heat Mass Transfer 2020;56:1833-43. https://doi.org/10.1007/s00231-020-02815-y.

[42] Yildırım C. Theoretical investigation of a solar air heater roughened by ribs and grooves. Journal of Thermal Engineering 2017;4:1702-12. https://doi.org/10.18186/journal-of-thermal-engineering.365713.

[43] Dutta J, Kundu B. Thermal Analysis on Variable Thickness Absorber Plate Fin in Flat Plate Solar Collectors Using Differential Transform Method. Journal of Thermal Engineering 2020. https://doi.org/10.18186/thermal.672169.

[44] Zidani C. Cfd simulation of thermo-aeraulic fields in a channel with multiple baffle plates. Journal of Thermal Engineering 2018;4:2481-95. https://doi.org/10.18186/thermal.465696.

[45] Singh J. Thermo hydraulic performance of solar air duct having triangular protrusions as roughness geometry. Journal of Thermal Engineering 2015;1. https://doi.org/10.18186/jte.01332.

[46] Solar Engineering of Thermal Processes, 4th Edition | Wiley. WileyCom n.d. https://www.wiley.com/enin/Solar+Engineering+of+Thermal+Processes\%2C+4th+Edition-p-9780470873663 (accessed May 9, 2020).

[47] Abdelkader TK, Zhang Y, Gaballah ES, Wang S, Wan Q, Fan Q. Energy and exergy analysis of a flat-plate solar air heater coated with carbon nanotubes and cupric oxide nanoparticles embedded in black paint. Journal of Cleaner Production 2019:119501. https://doi.org/10.1016/j.jclepro.2019.119501.

[48] Klein SA. Calculation of the monthly-average transmittance-absorptance product. Solar Energy 1979;23:54751. https://doi.org/10.1016/0038-092X(79)90083-5.

[49] Klein SA. Calculation of flat-plate collector loss coefficients. Solar Energy 1975;17:79. https://doi.org/10.1016/0038-092X(75)90020-1.

[50] Kalogirou SA. Solar Energy Engineering: Processes and Systems. Academic Press; 2013.

[51] Verma SK, Tiwari AK, Chauhan DS. Experimental evaluation of flat plate solar collector using nanofluids. Energy Conversion and Management 2017;134:103-15. https://doi.org/10.1016/j.enconman.2016.12.037. 
[52] Wylie, E. B., Streeter, V. L. Fluid transients. New York.: McGraw-Hill.; 1978.

[53] Solar Engineering of Thermal Processes, 4th Edition | Wiley n.d. https://www.wiley.com/enus/Solar+Engineering+of+Thermal+Processes, +4th+Edition-p-9780470873663 (accessed May 19, 2020).

[54] Farahat S, Sarhaddi F, Ajam H. Exergetic optimization of flat plate solar collectors. Renewable Energy 2009;34:1169-74. https://doi.org/10.1016/j.renene.2008.06.014.

[55] Entropy generation through heat and fluid flow (Book, 1982) [WorldCat.org] n.d. https://www.worldcat.org/title/entropy-generation-through-heat-and-fluid-flow/oclc/8475519 (accessed May 19, 2020).

[56] Moffat RJ. Describing the uncertainties in experimental results. Experimental Thermal and Fluid Science 1988;1:3-17. https://doi.org/10.1016/0894-1777(88)90043-X.

[57] Bejan A, Kearney DW, Kreith F. Second Law Analysis and Synthesis of Solar Collector Systems. J Sol Energy Eng 1981;103:23-8. https://doi.org/10.1115/1.3266200.

[58] Bejan A. Extraction of exergy from solar collectors under time-varying conditions. International Journal of Heat and Fluid Flow 1982;3:67-72. https://doi.org/10.1016/0142-727X(82)90002-9. 